\title{
In situ drag coefficient measurements for rooftop trees
}

\author{
Akio Koizumi ${ }^{1} \cdot$ Misato Shimizu $^{1} \cdot$ Yoshihisa Sasaki $^{1} \cdot$ Takuro Hirai $^{1}$
}

Received: 29 January 2016/Accepted: 1 April 2016/Published online: 18 May 2016

(C) The Japan Wood Research Society 2016

\begin{abstract}
To evaluate the drag coefficients for roof-top tree crowns, previously developed field test methods for monitoring wind speed, wind direction, and stem deflection were improved using solar cells as a source of power. A field test was conducted for a Norway spruce and a shirakanba located on a rooftop. The drag coefficients showed large variations during low wind speeds, which were caused by the flexural vibration of the tree trunk due to the fluctuating wind speed. To compensate for this effect, the upper percentage of drag coefficients obtained for the $0.5 \mathrm{~m} / \mathrm{s}$ wind speed classes were used for the exponential regression for drag coefficient as a function of wind speed. As a result, a conservative evaluation of drag coefficients for a greater range of wind speeds could be established instead of using all data. The drag coefficients at $30 \mathrm{~m} / \mathrm{s}$ wind speed were estimated to be 0.594 for the Norway spruce, and 0.154 for the shirakanba using the upper $50 \%$ of the data. The exponential function convergence was more gradual for the spruce than for the shirakanba, which may be affected by a difference in the streamlining behavior.
\end{abstract}

Keywords Drag coefficient - Windthrow resistance . On-site measurement · Picea abies - Betula platyphylla var. japonica

Part of this study was presented at the 63th Annual Meeting of the Japan Wood Research Society in Morioka, March 2013.

Akio Koizumi

akoizumi@for.agr.hokudai.ac.jp

1 Graduate School of Agriculture, Hokkaido University, N9 W9, Sapporo 060-8589, Japan

\section{Introduction}

In recent years, rooftop greening has gained popularity and is used on urban buildings to reduce the building's thermal load [1]. Planting trees instead of grasses is advantageous, as they provide shade on the roof terrace, thereby providing recreational sites for people and creating a biotope. However, the risk of windthrow for roof top trees is higher than for those grown on the ground because wind speed at rooftop is higher and the trees have limited resistance to uprooting due to the thin substrate of roof terraces. Therefore, the wind force acting on rooftop tree crowns should be evaluated quantitatively to evaluate the risk of windthrow.

Wind forces acting on the tree crown have been estimated by wind tunnel studies for various tree species [2-5]. However, it may be preferable to evaluate the drag induced by the actual wind, with fluctuations in speed and direction, to analyze windthrow risks for trees. For this reason, Koizumi et al. [6] developed a test method to evaluate actual-size trees in the field. The test method involves simultaneous monitoring of wind speed and stem deflection.

In the present study, we used the Koizumi et al. [6] method with improved control of power resources. The relationship between wind speed and drag coefficient was evaluated using different data filtering techniques. Based on the results, the uprooting resistance of rooftop trees against strong winds is discussed.

\section{Materials and methods}

\section{Sample site and trees}

The test site was the rooftop of a two-story building measuring $92 \mathrm{~m}$ north to south and $35 \mathrm{~m}$ east to west. The 
height of the rooftop was $7.4 \mathrm{~m}$ above ground level. The sample trees included a Norway spruce (Picea abies) and a shirakanba (Betula platyphylla var. japonica) planted in 430-mm-thick soil at the northern margin of the rooftop, where wind flows in an east-west direction (Fig. 1; Table 1). Since there are no buildings higher than the test site in east and west adjacent areas of the northern part of the rooftop, the relationship between wind speed and drag in the east-west direction was analyzed in this study. The wind direction was found to be comparatively uniform at the test area in preliminary measurement for wind flow distribution. The shirakanba tree located southeast of the Norway spruce. Although the two crowns of both trees were not overlapped in east to west direction, the air flow around the shirakanba caused by westerly wind might have been affected by the Norway spruce.

\section{Field test}

The field test involved monitoring wind speed and stem deflections, as shown in Fig. 2. The north-south and eastwest components of the wind speed were monitored using an ultrasonic anemometer (Young Company, Model 85000) placed on the western side of the spruce specimen. The height of the anemometer was adjusted to $2.3 \mathrm{~m}$ above the rooftop, to approximate the height of the wind pressure centers for the two specimens. Stem deflections of the two sample trees were measured using self-made middle-ordinate gauges (Fig. 3) screwed onto the stems. The centermounted displacement transducers detected the deflection over the gage spans, which were 770 and $500 \mathrm{~mm}$ for the spruce and shirakanba specimens, respectively. The power for the anemometer and the data logger was supplied by a $12 \mathrm{~V}$ battery connected to a $12 \mathrm{~V}-8 \mathrm{~W}$ solar panel. The measurements were conducted continuously from August 7 to October 16 in 2012.

\section{Estimation of the crown area and height of wind pressure center}

The horizontal projected areas for the sample crowns were obtained from the bitmap images converted from crown photographs taken from the east. Outlines of the crowns were traced and binarized to the bitmap image. The height of the wind pressure center was assumed to be the height of the gravity center of the image.

\section{Tree stem bending test}

To estimate wind forces applied on the sample trees from stem deflections, bending tests of the trees were conducted on calm days during the measurement period. Bending below the elastic limit was achieved by physically pulling the stem westward. The applied force was measured using a load cell that connected the sling, which was tied to the stem at a height of $2 \mathrm{~m}$. The load and stem deflection, measured using the middle ordinate gauge, were recorded in a data logger at $5 \mathrm{~Hz}$ intervals.

From the elastic relationship between the applied force $(F)$ and the stem deflection $(\delta)$, the stem stiffness factor $(K)$ defined was determined as follows:

$K=\frac{F}{\delta}$

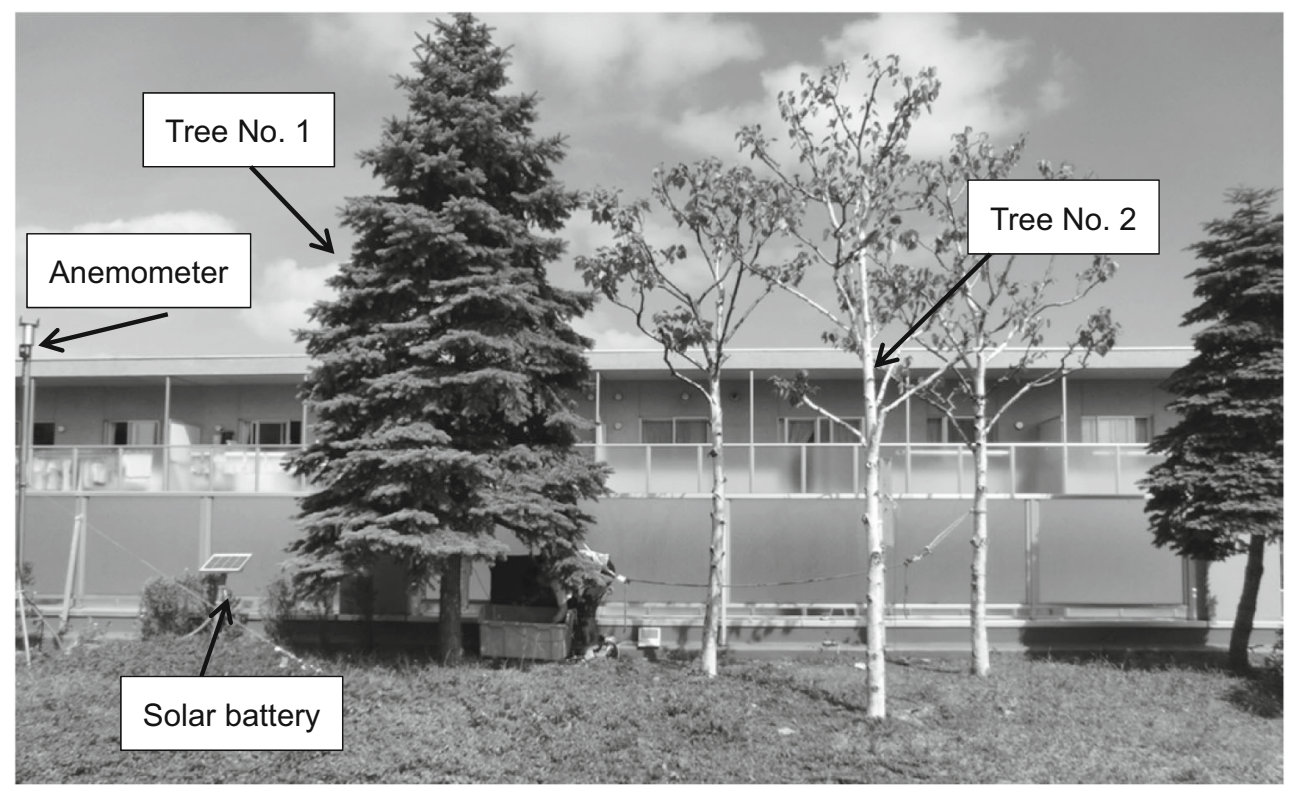

Fig. 1 Sample tree Nos. 1 and 2 with middle-ordinate gauges on their trunks (viewed from the south) 
Table 1 Dimensions of sample trees

\begin{tabular}{|c|c|c|c|c|c|c|c|c|c|c|}
\hline No. & Species & $H(\mathrm{~m})$ & $H_{\mathrm{D}}(\mathrm{m})$ & $D(\mathrm{~cm})$ & $L_{\mathrm{c}}(\mathrm{m})$ & $B_{\mathrm{c}}(\mathrm{m})$ & $A_{\mathrm{c}}\left(\mathrm{m}^{2}\right)$ & $A_{\mathrm{c}-\mathrm{s}}\left(\mathrm{m}^{2}\right)$ & $H_{\mathrm{w}}(\mathrm{m})$ & $H_{\mathrm{w}-\mathrm{s}}(\mathrm{m})$ \\
\hline 1 & Norway spruce & 4.70 & 0.77 & 15.4 & 4.36 & 2.33 & 5.437 & 5.079 & 2.182 & 1.793 \\
\hline 2 & Shirakanba & 3.97 & 1.28 & 8.09 & 2.30 & 1.24 & 1.042 & 1.426 & 3.037 & 2.820 \\
\hline
\end{tabular}

$H$, tree height; $H_{\mathrm{D}}$, deflection sensor height; $D$, diameter at the deflection sensor height; $L_{\mathrm{c}}$, crown length; $B_{\mathrm{c}}$, crown breadth (north-south direction); $A_{\mathrm{c}}$, horizontal projected area of crown calculated from binarized image; $A_{\mathrm{c}-\mathrm{s}}$, crown area calculated assuming a triangle crown for spruce and an diamond one for shirakanba; $H_{\mathrm{w}}$, height of wind pressure center estimated from gravity center of crown area, $H_{\mathrm{w}-\mathrm{s}}$, wind pressure center height assuming a triangle crown for spruce and an diamond one for shirakanba

Fig. 2 Schematic diagram of the measurements and the explanations for the variables used in Eq. 2, $H_{\mathrm{D}}$, deflection sensor height; $H_{\mathrm{F}}$, loading height for stem bending test; $H_{\mathrm{W}}$, height of wind pressure center

Fig. 3 Middle-ordinate gauge. $L$ is the length of a gauge span
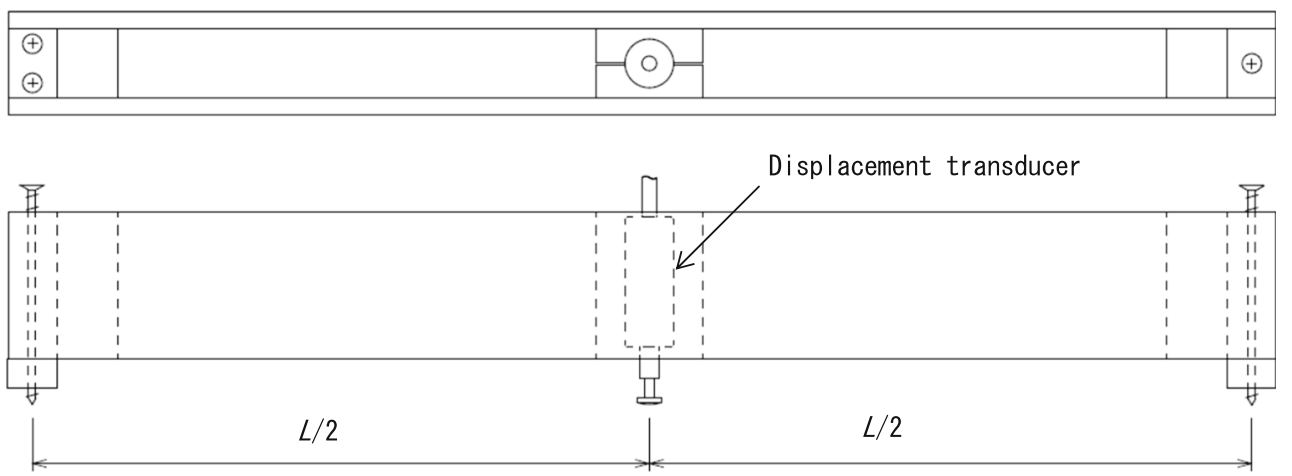

\section{Data processing}

The data series was divided into 1-h segments and averaged every second. Thus, each segment consisted of 3600 records. The segments that included records with wind speed above $10 \mathrm{~m} / \mathrm{s}$ in the east-west direction were extracted for the analysis. The stem deflection data observed at a wind speed less than $1 \mathrm{~m} / \mathrm{s}$ were averaged for each extracted segment. Then the stem deflection data were corrected by subtracting the average value. This correction 
was performed to correct for the slippage of the deflection sensor that occurred during the measurement period.

The wind force acting on the crown $\left(P_{\mathrm{w}}\right)$ can be calculated from $K$ and $\delta$ using Eq. 2 as follows:

$P_{\mathrm{W}}=\frac{K\left(H_{\mathrm{F}}-H_{\mathrm{D}}\right) \delta}{\left(H_{\mathrm{W}}-H_{\mathrm{D}}\right)}$

where $H_{\mathrm{W}}$ is the height of the wind pressure center, $H_{\mathrm{F}}$ is the height of load point for the stem bending test, and $H_{\mathrm{D}}$ is the height of the deflection sensor (Fig. 2). $P_{\mathrm{w}}$ is also expressed as Eq. 3, which defines the drag coefficient $\left(C_{\mathrm{D}}\right)$ as follows:

$P_{\mathrm{W}}=\frac{1}{2} C_{\mathrm{D}} \rho A_{\mathrm{C}} U^{2}$

where $\rho$ is the air density, $A_{\mathrm{C}}$ is the horizontally projected crown area, and $U$ is the wind speed. The constant $\rho$ was given a value of $1.20 \mathrm{~kg} / \mathrm{m}^{3}$.

$C_{\mathrm{D}}$ was calculated for every 1 -s record using Eq. 4, which was derived by substituting Eq. 2 into Eq. 3 as follows:

$C_{\mathrm{D}}=\frac{2 K\left(H_{\mathrm{F}}-H_{\mathrm{D}}\right) \delta}{\rho A_{\mathrm{C}}\left(H_{\mathrm{W}}-H_{\mathrm{D}}\right) U^{2}}$

\section{Results and discussion}

\section{Crown area and wind pressure center height}

Examples of the binarized bitmap images for two sample crowns are shown in Fig. 4. Since the shirakanba tree had been intensively pruned, the image without the enclosed crown circumference areas (image B in Fig. 4) was used for the analysis. The projected crown area $\left(A_{\mathrm{C}}\right)$, and the height of the wind pressure center $\left(H_{\mathrm{W}}\right)$, for the sample crowns obtained by the planimetric method using the bitmap images are presented in Table 1, along with those calculated from simplistic geometric assumptions. For the spruce, the crown was assumed to form a triangle shape, whose base length and height were the crown width and the crown length, while for the shirakanba, the crown formed a diamond shape, whose breadth and height were those of the crown. A triangle crown shape has often represented the excurrent branching pattern of conifers, and diamond shape was assumed for the decurrent branching pattern of broadleaved trees. The ratios of geometrically assumed crown area to bitmap image area were found to be 0.934 and 1.369 for the spruce and the shirakanba, respectively. For the shirakanba crown, when the area enclosed by the circumference of the crown was included in the crown area, as shown in image $\mathrm{C}$ in Fig. 4, the crown area accounted for $1.406 \mathrm{~m}^{2}$, which was close to the $1.426 \mathrm{~m}^{2}$ value obtained for the diamond shape.

Although the areas of the triangle and the diamond are the same, the height of the gravity center $\left(H_{\mathrm{W}-\mathrm{S}}\right)$ differed between the two shapes (Table 1 ). The ratios of $H_{\mathrm{W}-\mathrm{S}} / H_{\mathrm{W}}$ (triangle or diamond assumption/actual image) were found to be 0.821 and 0.929 for the spruce and the shirakanba, respectively. Consequently, the triangle assumption would overestimate the $C_{\mathrm{D}}$ by $48 \%$ for the spruce, and underestimate the $C_{\mathrm{D}}$ by $17 \%$ for the shirakanba according to the calculation based on Eq. 4 .

\section{Stiffness of the stem}

The relationship between the applied force and the stem deflection observed in the tree bending tests were found to be almost linear, and therefore adequate for determining
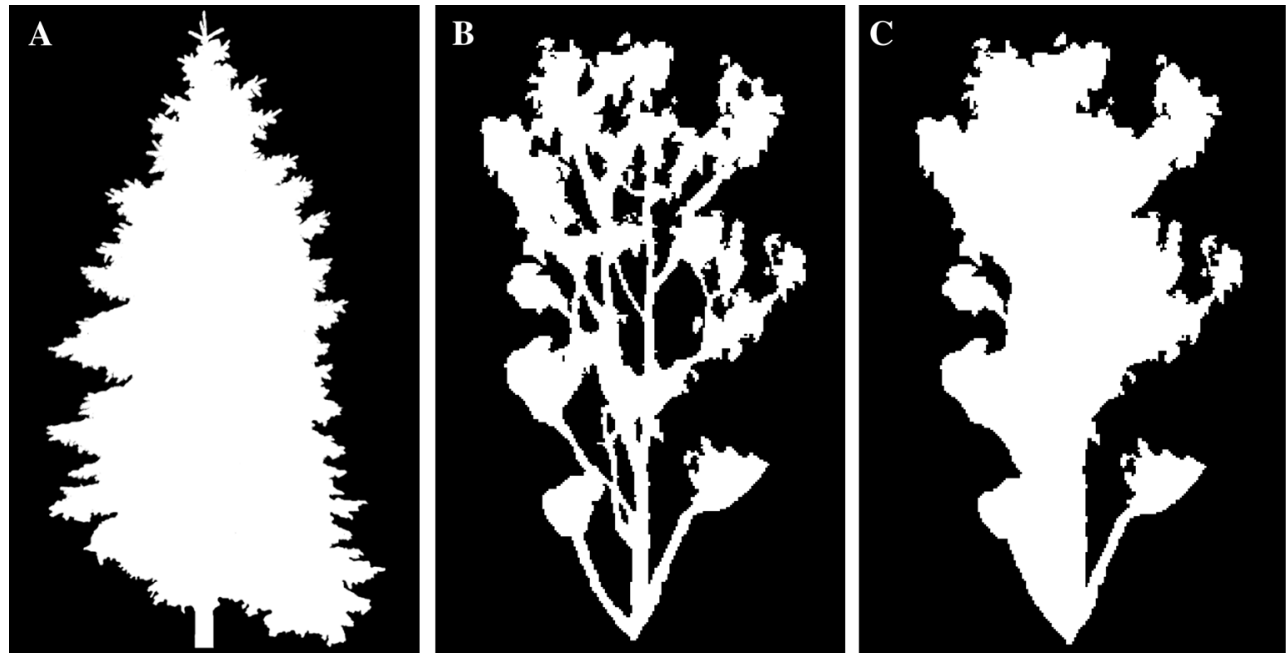

Fig. 4 Binarized images of sample tree crowns. a Norway spruce, b Shirakanba, c Shirakanba (enclosed areas were filled) 
the stiffness factor $(K)$. The $K$ s were found to be 630.7 and $415.9 \mathrm{~N} / \mathrm{mm}$ for the spruce and the shirakanba, respectively.

\section{Evaluation of the drag coefficient}

Generally $C_{\mathrm{D}}$ is expressed in relation with Reynolds number, which is affected by both inertia and viscosity, in fluid mechanics. In this research, $C_{\mathrm{D}}$ is expressed as a function of wind speed, which is convenient for estimating wind force at infrequent high wind speed. This expression has been a usual procedure used in windthrow analysis for trees [2, 5-9].

The number of days with wind speeds recorded above 10 m/s was 3 in August, and 13 in October for the westerly wind, and 4 in August, 3 in September, and 4 in October for the easterly wind. In total, 70 segments (70-h records) for the west wind and 51 segments for the east wind were analyzed. The maximum wind speed observed was $18.9 \mathrm{~m} / \mathrm{s}$ for the westerly wind and $15.7 \mathrm{~m} / \mathrm{s}$ for the easterly wind.

The relationship between wind speed $(U)$ and apparent $C_{\mathrm{D}}$ calculated from Eq. 4 showed a similar pattern for the westerly and easterly winds (Fig. 5). However, $C_{\mathrm{D}}$ variations for the easterly wind were slightly greater than those for the westerly wind. It is possible that the spruce crown, which was located to the east of the anemometer, might affect the east-wind measurements. Therefore, 70 segments for the westerly wind were used for the analysis.

$C_{\mathrm{D}}$ tends to decrease with an increase in $U$ because of the decrease in projected crown area caused by tree crown streamlining $[2,5-8]$. Therefore, it is necessary to develop an adequate function for the $U-C_{\mathrm{D}}$ relationship to estimate $C_{\mathrm{D}}$ for stormy gales, such as $30 \mathrm{~m} / \mathrm{s}$, using the data collected at wind speeds less than $20 \mathrm{~m} / \mathrm{s}$.

In a previous study [6], such curve-fitting was based on the relationship between $U$ and $C_{\mathrm{D}}$, which was averaged for the $0.5 \mathrm{~m} / \mathrm{s}$ wind-speed classes. For this analysis, considerably large variations in $C_{\mathrm{D}}$ were found at low wind speeds. These variations were attributed to the backswaying behavior of tree trunks, which is due to the flexural vibration of a tree trunk caused by its cantilevered beam structure, which is anchored to the ground. The low or negative values of $C_{\mathrm{D}}$, attributed to this back-swaying behavior, should be cancelled. It may be necessary to use some upper values of $C_{\mathrm{D}}$ when fitting a curve based on the $U-C_{\mathrm{D}}$ relationship. To examine the effects of using percentiles of the $C_{\mathrm{D}}$ data, we extracted the upper $10,30,50$, and $100 \%$ of the data for each $0.5 \mathrm{~m} / \mathrm{s}$ wind-speed class. Fractional numbers were rounded up. The exponential function of Eq. 5, which demonstrated a good fit, was curve-fitted according to the relationship between $U$ and average $C_{\mathrm{D}}$ for the wind speed classes as shown in Fig. 6:
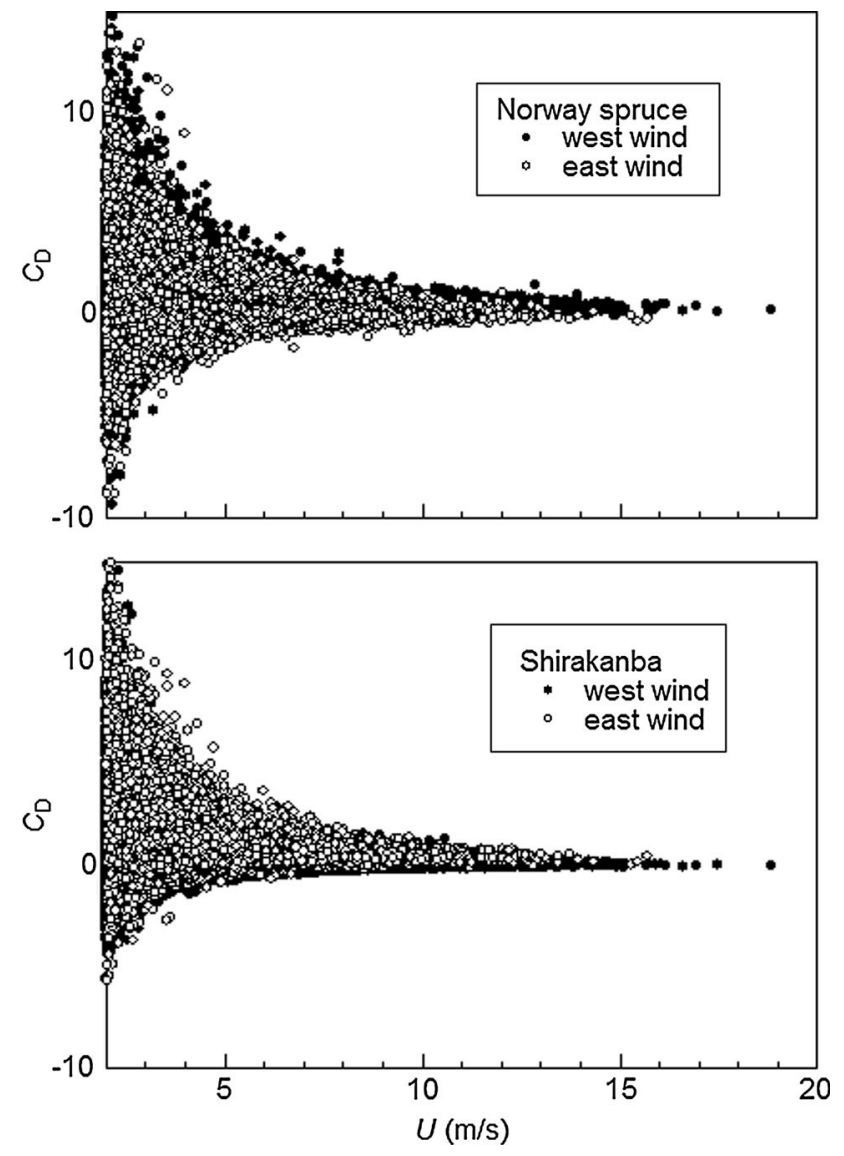

Fig. 5 Comparisons of drag coefficient $\left(C_{\mathrm{D}}\right)$ in relation with wind speed $(U)$ observed for westerly wind and easterly wind

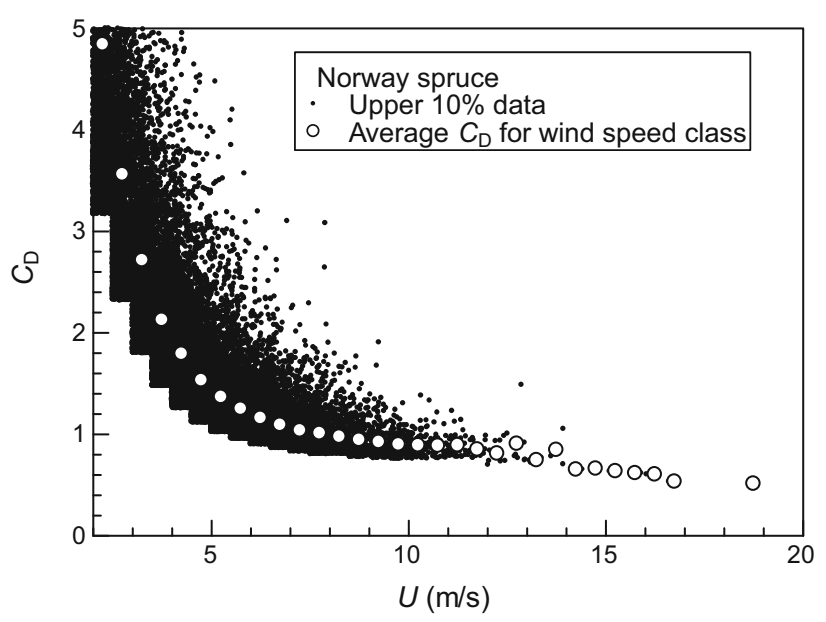

Fig. 6 An example of extracting the upper $10 \%$ of the data for $0.5 \mathrm{~m} / \mathrm{s}$ wind speed classes

$C_{\mathrm{D}}=a+b c^{U}$

where $a, b$, and $c$ are constants $(0<c<1)$. Constant $a$ is a convergence value of $C_{\mathrm{D}}$. 
Table 2 Estimated values for drag coefficient $\left(C_{\mathrm{D}}\right)$ using the exponential function

\begin{tabular}{llllll}
\hline Upper percent & \multicolumn{2}{l}{ Norway spruce } & & \multicolumn{2}{l}{ Shirakanba } \\
\cline { 2 - 3 } \cline { 6 - 6 } Used for curve fit & $10 \mathrm{~m} / \mathrm{s}$ & $30 \mathrm{~m} / \mathrm{s}$ & & $10 \mathrm{~m} / \mathrm{s}$ & $30 \mathrm{~m} / \mathrm{s}$ \\
\hline 10 & 0.864 & 0.592 & & 0.300 & 0.291 \\
30 & 0.681 & 0.651 & & 0.201 & 0.198 \\
50 & 0.602 & 0.594 & & 0.155 & 0.154 \\
100 & 0.429 & 0.429 & & 0.066 & 0.066 \\
\hline
\end{tabular}

The $C_{\mathrm{D}}$ at $30 \mathrm{~m} / \mathrm{s}$ winds, as estimated by Eq. 5 using the upper $10 \%$ of the data, were found to be 1.38 times and 4.41 times greater than those using all data for the spruce and the shirakanba, respectively (Table 2). It could be said that the conservative estimation for $C_{\mathrm{D}}$ can be made using the upper percentage of data. The average values for $C_{\mathrm{D}}$ observed at wind speeds over $10 \mathrm{~m} / \mathrm{s}$ were 0.375 and 0.082 for the spruce and the shirakanba, respectively. The estimated $C_{\mathrm{D}}$ at wind speed of $30 \mathrm{~m} / \mathrm{s}$, using the upper $50 \%$ of the data, were found to be greater than the average $C_{\mathrm{D}}$ observed at wind speeds over $10 \mathrm{~m} / \mathrm{s}$. Therefore, averages of the upper $50 \%$ of the data were used for the curve-fit of Eq. 5 in this study.

The convergence rate of Eq. 5 is influenced by the constant $c$ in Eq. 5. The greater $c$ becomes, the more gradual the convergence rate becomes (Fig. 7). $C_{\mathrm{D}}$ for the spruce decreased more gradually than it did for shirakanba with the increase in wind speed, especially at low wind speeds. This could be attributed to the differences in branch and leaf flexibility between the two species, which affected the streamlining behavior of the tree crowns.

The estimated $C_{\mathrm{D}}$ for the Norway spruce crown at a wind speed of $30 \mathrm{~m} / \mathrm{s}$ was found to be 0.594 , which was considerably greater than 0.35 , which had been reported by Mayhead [2] for Sitka spruce. This could partly be attributed to the differences in the test conditions: an outdoor measurement versus a wind tunnel test. More turbulent airflow tends to predominate in the outdoor conditions, and it might increase the drag of a tree crown [9]. The estimated $C_{\mathrm{D}}$ for the shirakanba crown, at a wind speed of $30 \mathrm{~m} / \mathrm{s}$, was 0.154 . The $C_{\mathrm{D}}$ would have been estimated at 0.110 if the area enclosed by the circumference of the crown was included in the crown area as shown in image $\mathrm{C}$ in Fig. 4. A further discussion as to the definition of the crown area is necessary when dealing with an intensively pruned crown.

\section{Uprooting moment}

The moment at the tree base induced by wind force $\left(M_{0}\right)$ can be calculated from Eq. 6:

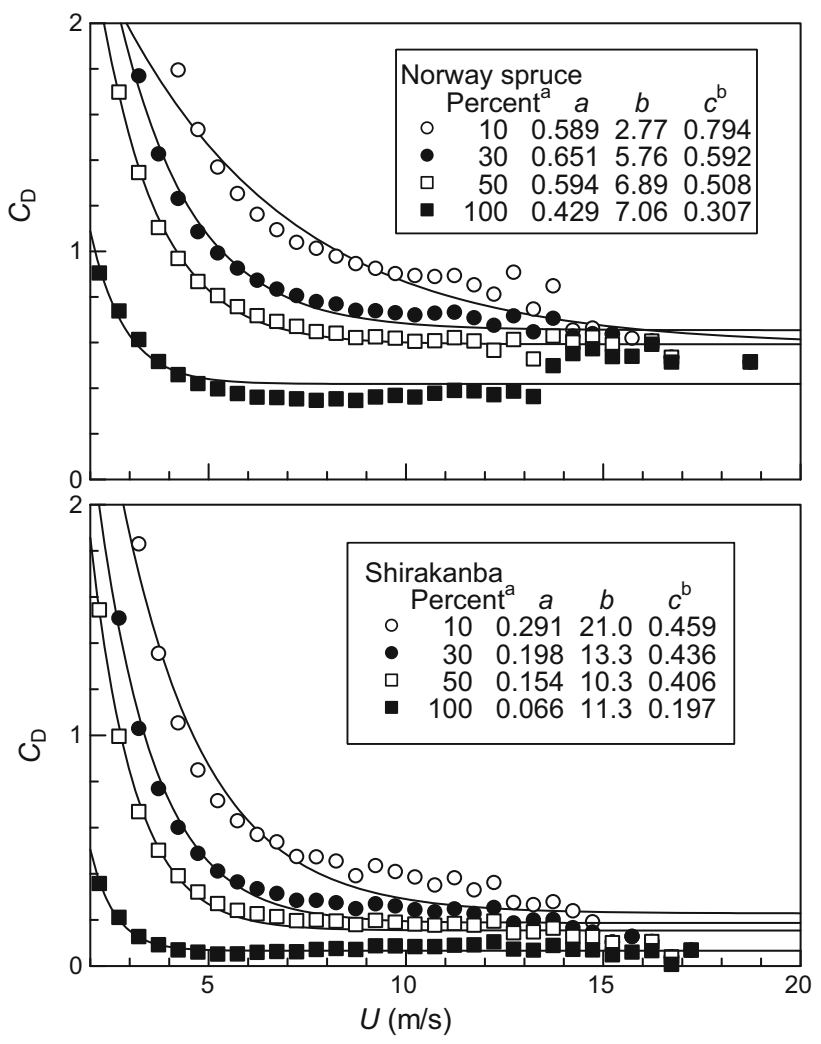

Fig. 7 Relationship between wind speed $(U)$ and drag coefficient $\left(C_{\mathrm{D}}\right)$. Each plot is an average, calculated for the $0.5 \mathrm{~m} / \mathrm{s}$ wind speed class. Letter $a$ upper data percentage used for curve-fitting. Letter $b$ variables $a, b$, and $c$ are shown in Eq. 5

$M_{0}=P_{\mathrm{W}} H_{\mathrm{W}}=\frac{1}{2} C_{\mathrm{D}} \rho A_{\mathrm{C}} U^{2} H_{\mathrm{W}}$

The $M_{0}$ values at $30 \mathrm{~m} / \mathrm{s}$ wind speed for the spruce and the shirakanba crowns were calculated to be 3.805 and $0.263 \mathrm{kNm}$, respectively. It can be concluded that tree management, such as reducing tree height and intensive pruning have led to relatively small $M_{0}$ values, which reduced the windthrow risks for the test site.

The uprooting moments for the sample trees were estimated using regression equations calculated using the breast height diameter and the uprooting moment, which was obtained from the pulldown tests of Norway spruce and shirakanba trees conducted in Hokkaido [10]. The uprooting moments for the Norway spruce and the shirakanba were estimated to be 18.1 and $5.19 \mathrm{kNm}$, respectively, which were sufficiently greater than the estimated $M_{0}$ values experienced by the sample trees at $30 \mathrm{~m} / \mathrm{s}$ wind speed. The critical wind speeds necessary to cause uprooting were calculated to be $65 \mathrm{~m} / \mathrm{s}$ for the spruce, and $133 \mathrm{~m} / \mathrm{s}$ for the shirakanba specimen, using Eq. 6. However, additional pulldown tests on rooftop trees should be conducted to predict windthrow risk accurately, because the uprooting moment for a rooftop tree would be considerably smaller than that for a tree grown in the field. 


\section{Conclusions}

1. An in situ measurement system to determine drag coefficient $\left(C_{\mathrm{D}}\right)$ of a tree crown, using a solar battery as the power source, was established.

2. Conservative evaluation for $C_{\mathrm{D}}$ was obtained using curve-fit of the exponential function on the upper $50 \%$ of the data for wind speed classes.

3. $C_{\mathrm{D}} \mathrm{s}$ of the sample tree crowns planted on the rooftop at $30 \mathrm{~m} / \mathrm{s}$ wind speed were estimated as 0.594 for the Norway spruce and 0.154 for the shirakanba using the upper $50 \%$ of the data.

4. The convergence of the exponential equation fitted on the $U-C_{\mathrm{D}}$ relationship was more gradual for the Norway spruce than for the shirakanba crown, especially at low wind speeds.

Acknowledgments This study was supported in part by JSPS KAKENHI (21580169).

\section{References}

1. Cao J, Tamura Y, Yoshida A (2012) Wind tunnel study on aerodynamic characteristics of shrubby specimens of three tree species. Urban For Urban Green 11:465-476
2. Mayhead GJ (1973) Some drag coefficients for British forest trees derived from wind tunnel studies. Agric Meteorol 12:123-130

3. Johnson RC, Ramey GE, O'Hagan DS (1982) Wind induced forces on trees. J Fluid Eng 104:25-30

4. Murakami S, Deguchi K, Takahashi T (1984) Shelter effects of trees as wind-breaks (in Japanese). In: Proceedings of symposium on wind engineering, Tokyo, pp 129-136

5. Ishikawa $\mathrm{H}$ (2005) Experimental study on flow characteristics of trees (in Japanese). Nagare 24:483-490

6. Koizumi A, Motoyama J, Sawata K, Sasaki Y, Hirai T (2010) Evaluation of drag coefficients of tree crowns by a field test method. J Wood Sci 56:189-193

7. Vollsinger S, Mitchell S, Byrne KE, Novak MD (2005) Wind tunnel measurements of crown streamlining and drag relationships for several hardwood species. Can J For Res 35:1238-1249

8. De Langre E, Gutierrez A, Cosse J (2012) On the scaling of drag reduction by reconfiguration in plants. CR Mec 340:35-40

9. Kane B, Smiley ET (2006) Drag coefficients and crown area estimation of red maple. Can J For Res 36:1951-1958

10. Sato H, Torita H, Masaka K, Kon H, Shibuya M (2009) Analysis of windthrow factors in windbreaks: in the case of Bibai, Hokkaido by Typhoon No.18 in 2004 (in Japanese). J Jpn For Soc 91:307-312 